\title{
1898: PRENSA Y OPINIÓN PÚBLICA \\ EN ESPAÑA Y LOS ESTADOS UNIDOS
}

\section{8: PRESS AND PUBLIC OPINION \\ IN SPAIN AND THE UNITED STATES}

\section{AUTOR}

\section{Juan Jiménez Mancha}

Historiador. Articulista en varias publicaciones científicas y divulgativas (España) juanjimenez@hotmail.com

\section{RESUMEN}

En España, a principios de 1898 la prensa española gozaba de una credibilidad y un auge indudable. Mientras tanto, en Estados Unidos nacía la "prensa amarilla", donde los periodistas desinformaban desde un punto de vista crítico y malicioso, aprovechando para inculcar en los ciudadanos la opinión que necesitaban que tuviesen con respecto a la guerra, transformando los hechos o inventándolos. España acogió esta idea, pero después de sacarle todo su jugo, se vino a pique, consiguiendo el descrédito y la pérdida de miles de lectores. A partir de entonces, cuando los ciudadanos se percataron del engaño, los que siguieron leyendo la prensa lo hicieron desde un punto de vista neutro, evitando así el engaño.

\section{PALABRAS CLAVE}

Prensa - Opinión Pública - España - Estados Unidos 


\section{ABSTRACT}

In Spain, in early 1898, the Spanish press enjoyed a boom credibility and undeniable. Meanwhile, the United States was born the "yellow press", where the uninformed journalists from critically and malicious advantage to instill in people the view that they needed they had about the war, transformed or invented facts. Spain welcomed this idea, but after get all the juice, he came under, getting discredit and loss of thousands of readers. Thereafter, when citizens realized the deception, which continued reading the newspaper did so from a neutral point of view, avoiding deception.

\section{KEY WORDS}

Newspapers - Public Opinion - Spain - United States

\section{ÍNDICE}

1. La prensa en España.

2. La situación en Estados Unidos.

3. Conclusión.

4. Bibliografía.

\section{La prensa en España.}

A principios de 1898 la prensa española vivía un momento de optimismo y estabilidad, contándose con un elevado número de publicaciones de amplia tipología. No existía ningún otro medio de comunicación de masas. Los periódicos disfrutaban del monopolio de la información cotidiana, constituyendo sus páginas la única ventana al mundo para el ciudadano de a pie. El alto índice de analfabetismo, más o menos de dos tercios de la población, no impedía la venta cada vez mayor de ejemplares -cuatro diarios luchaban por los cien mil de tirada- ni la gran proliferación 
de cabeceras. El pueblo necesitaba de alguien que le contara lo que sucedía alrededor; el que no sabía leer se conformaba con echar la lectura, muchas veces en corrillo, de los más capacitados. Para mayor respeto de todos, los diarios, normalmente de cuatro hojas, solían resultar físicamente imponentes; con frecuencia de $60 \mathrm{~cm}$. de largo por 42 de ancho, dimensiones encuadradas dentro del formato conocido como sábana. Todo lo que se decía en aquellas enormes páginas solía ser aceptado sin más como verdadero. Los escritores de periódicos tenían, por tanto, motivos para creerse importantes y eran conscientes de su labor, pero no del cuidado que se deban exigir a sí mismos al ocupar tan privilegiada y delicada posición en la sociedad. Desde las páginas de la práctica totalidad de diarios y revistas se animará a la opinión pública -en curiosa mezcolanza con toros, verbenas y pasado imperial- a profesar un hondo y entusiasta deseo de guerra contra los Estados Unidos. Comunicadores ciegos para un pueblo con los ojos vendados: ¿Quién arrastró a quién? Los escritores, en su mayor parte ingenuos y poco preparados, no supieron ver e interpretar, ya que la mera información quedaba lejos de sus pretensiones, con criterios que fueran más allá de la incultura que había ido uniformando al pueblo español.

\section{La situación en Estados Unidos.}

Mientras tanto en los Estados Unidos, principal hostigador de los intereses españoles en las colonias, se venía gestando desde 1895 un estado de la opinión pública también firmemente volcado en favor de la guerra. En aquel joven y poco conocido país se imponía, al igual que en los estados europeos más desarrollados, como Inglaterra y Alemania, el llamado "periodismo de empresa". Bajo esta expresión se intentaba resumir la nueva actitud de algunas grandes cabeceras que, apoyadas en el creciente negocio de la publicidad y en el juego de la libre competencia, procuraban, ante todo, elevar la venta de ejemplares en busca del puro beneficio económico. Este "periodismo de empresa" era en 1898 el hegemónico en los Estados 


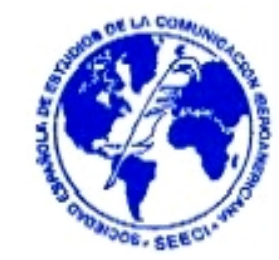

Unidos, circunstancia coincidente con el auge de los anhelos imperialistas, más suavemente llamados expansionistas, de un buen número de personajes socialmente relevantes que ocupaban posiciones claves en distintos estamentos del país, como el Ejército y el Senado. Uno de estos sujetos, William Randolph Hearst, el gran magnate de la prensa, conseguirá que sus periódicos se transformen en la mejor arma política para lograr el clima apetecido de odio hacia lo español y deseo de guerra. Para obrar con disimulo se bañará este ímpetu con una desproporcionada compasión hacia el pueblo cubano. El New York Journal, propiedad de Hearst, y el New York World, de su gran rival Joseph Pulitzer, competirán de un modo a menudo despiadado por acaparar la mayor cifra posible de compradores (el Journal llegará a situar su retor en la venta del millón de ejemplares diarios). Los conflictos en las colonias españolas, sobre todo en Cuba, conformarán el principal filón para el logro de estos intereses empresariales. Los grandes titulares, exagerando o inventando los acontecimientos, incrementarán las ventas de un modo vertiginoso, a la vez que fueron creando un estado de opinión pública en donde sólo tenía cabida el deseo de intervención armada. Lo que se vendía y compraba eran, en teoría sentimientos humanitarios. Hearst y Pulitzer enriquecieron sus bolsillos y lograron un rápido ascenso social, siempre en nombre de la humanidad, al manejar hábilmente los sentimientos de sus compatriotas, tan ingenios como los de los españoles en su país. Las raíces de tal actitud arrancan con el surgimiento, a finales de los ochenta, del denominado "periodismo amarillo", del que primero el World, y después el Journal, serán sus principales baluartes, y del que es justo desligar a otros diarios más honestos como el New York Herald, Evening Post o el Sun (aunque a veces los mismos se vean contaminados por este peligroso veneno). Esta nueva manera de reflejar la realidad comenzará a ser estudiada con profundidad en Europa a partir de 1898, cuando ya lo pernicioso de sus efectos habían desnaturalizado los conflictos en Cuba. La publicación en mayo de ese año de un extenso artículo en la revista francesa La Revue des Revues, en teoría neutral, acarreará la aparición en España de algunos escritos de destacados periodistas, como Luis Besses y Emilia Pardo Bazán, en donde se analizará con estupor, al dictado de los datos de la Revue des Revues, 
tanto la mala fe de las técnicas de Hearst y Pulitzer como la audacia entendida como deleznable, de los reporteros sensacionalistas norteamericanos. Según se desprende de estos artículos, la "prensa amarilla" apostó por la guerra contra España adoptando tan sólo las mismas medidas comerciales y morales características de estos periódicos como empresa, en clara evolución continuista, y en donde el fin último seguía siendo la mayor venta de ejemplares. Las actuaciones de los "cerebros amarillos" son condenadas por falta de ética y moral, exponiéndose múltiples ejemplos de insólita y lamentable actualidad cien años después. Hearst y Pulitzer, cada vez más osados e interesados, tocaron la esfera de la política manipulando o inventando las declaraciones de los más altos personajes de la vida política mundial, como Bismarck, el Príncipe de Gales o el prometedor Theodore Roosevelt. El afán por lograr las "sensaciones más auténticas" no desdeñaba ningún medio. A algunos comerciantes, por ejemplo, se les proponía desde las redacciones la ejecución del llamado "crimen anuncio", fechoría amarillista construida sobre la base de un pacto periódico-tienda, a través del cual se articulaba un robo espectacular al establecimiento que garantizase una noticia sensacional, publicidad para la tienda y, por supuesto, la ausencia de pruebas para la policía. Otro acuerdo habitual permitía que las actrices en decadencia se inventaran el robo de sus joyas, lográndose otra vez noticias sensacionales y la fama de alguien necesitado de ella. Los periodistas sabían jugar a ambos lados de la ley, ya que también estaban facultados para transformarse en extraordinarios detectives, enviando a prisión, por medio de denuncias, a muchos infelices de dudosa culpabilidad. Las tiradas de los periódicos no cesaban de aumentar, mientras que los redactores estrujaban sus cerebros imaginando nuevos caminos para sobrecoger aún más a los lectores. Alcanzó fama una periodista que, en una ocasión, se hizo meter en un ataúd para ser enterrada durante más de un cuarto de hora, y que, en otra, protagonizó todos los pasos dados por un condenado hasta sentarse en una silla eléctrica con casco incluido. Para estos escritores norteamericanos lo principal era tocar la parte más blanda del corazón de los lectores; prácticamente hoy común en todo el mundo, como sabemos y padecemos. 
Este era el adulterado panorama periodístico que acogerá en los Estados Unidos, sobre todo a partir de 1895, las informaciones llegadas desde Cuba y España. La política de reconcentraciones del General Weyler supondrá de inicio el principal contenido a manipular. A partir de entonces la prensa se dedicará a tergiversar todo lo acaecido en las colonias, ideándose toda clase de atrocidades por parte de unos españoles siempre vistos, y caricaturizados, como bandoleros de Sierra Morena (criminales, sanguinarios, descerebrados, anacrónicos, etc.). Un folletín por entregas protagonizado por un personaje real, Evangelina Cisneros, causará un gran impacto entre el pueblo norteamericano por la gran variedad de ultrajes españoles violaciones, torturas, encarcelamientos, fugas heroicas, etc.- que articulaban cada truculento capítulo. Para conmover a todos los sentidos el J ournal publicará una serie de fotografías "hechas en el terreno", bajo el título de Los Hambrientos de Cuba, en donde se presentarán diferentes mujeres y niños cubanos, siempre escuálidos y afligidos, delante de un fondo sospechosamente invariable y en similares poses perfectas para el retrato fotográfico. No es de extrañar que a Cuba se la llegara a conocer como "la isla de las lágrimas", reservándose para los españoles el papel de crueles artífices de aquel dolor.

Como consecuencia de la explosión del Maine los partidarios de la paz tuvieron que empezar a esconderse. La prensa norteamericana obtuvo con este grave incidente su razón definitiva para entrar de una vez por todas en guerra. Lo sucedido, según ellos, desenmascaraba la perfidia inhumana de los españoles. Los grandes titulares acusadores apuntaron con descaro hacia la culpabilidad de España, mientras que en el Journal se ofrecían en portada 50.000 dólares a todo aquel que aportara pruebas incriminatorias sólo en este sentido, y nunca para aclarar el posible accidente. La verdad no era precisamente lo que se buscaba.

En lo sucesivo una frase del Journal se esgrimirá como slogan evocador de futuros aires de tragedia: "recordad el Maine". El drama, desde tierras norteamericanas, ya 


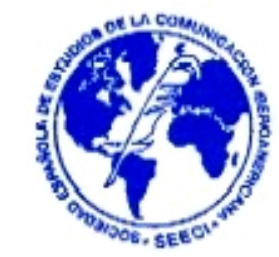

estaba en camino. El conflicto armado que se habría de desencadenar pasará a algunas Historias como "la Guerra de Hearst". Esta identificación puede parecer exagerada, pero delata el enorme e importante papel que adquirió la prensa norteamericana sensacionalista para crear un estado en la opinión pública cuyo final sólo podía ser la guerra. La Revue des Revues escarbará en el fondo de esta cuestión señalando lo siguiente: Es preciso, no obstante, no olvidar que la guerra a la que asistimos es casi obra exclusiva de dos grandes diarios de Nueva York, o más bien de los dos hombres que se encuentran a su cabeza: los señores Pulitzer y Hearst. La prensa debuta en un nuevo papel de "hacedora de guerras", apropiándose de lo que era un privilegio de los antiguos reyes o de los parlamentos más modernos.

El mundo periodístico español no poseía la solidez económica del norteamericano. Desde los diarios se influía en la opinión pública con medios más modestos y en apariencia menos llamativos, pero igualmente eficaces. El gusto por el sensacionalismo había arrancado en España en Julio de 1888, con motivo del famoso crimen de la calle Fuencarral. Para aclarar este turbio suceso, que conmocionó al país, varios periódicos, a los que se calificaría de insensatos, iniciaron una larga campaña en donde se combinaron algunos grandes titulares, descripciones morbosas, largas entrevistas a los implicados y toda clase de afirmaciones y juicios más propios de los tribunales. El afán por adueñarse de parcelas ajenas fue más ligero que en el caso norteamericano, pero el "juicio paralelo" orquestado desde la prensa anticipaba posturas abusivas que serán una constante en 1898. En un principio los problemas en las colonias apenas ocuparon espacios privilegiados en los periódicos. En la sociedad española preocupaban poco estos asuntos tan lejanos y ajenos al quehacer cotidiano. Con la llegada del 98, cargado de tensión, se abrirán nuevas secciones fijas, de relevancia progresiva, que derivarán hacia primeras planas dedicadas, cada vez más en exclusiva, a tales cuestiones. La prensa más seguida en todo el país será, con diferencia, la madrileña, sobre todos los cuatro diarios autoproclamados, aunque no lo eran tanto, independientes: La Correspondencia de España, desapasionada, siempre proministerial fuera cual fuese el gobierno; El 
Imparcial, muy respetado, aunque de imparcial tenía poco; El Liberal, progresista pero algo sensacionalista y el Heraldo de Madrid, vespertino muy popular, conocido como el "gorro de dormir de los madrileños". Junto a ellos se estaba desarrollando aún la llamada prensa de opinión, principalmente de partido, apartado en donde destacaban La Época, canovista; El Tiempo, órgano de Silvela; El Correo, de Sagasta; El Nacional, muy conservador; El País, republicano y muy radical; El Siglo Futuro, católico e integrista y El Globo, órgano de Castelar. También como de partido se puede tildar a la prensa militar, portavoz de las opiniones de este importante segmento de la población, en donde figuraban El Ejército Español, el más conservador y El Correo Militar y La Correspondencia Militar. Existían muchos más periódicos de gran diversidad ideológica, en general con tiradas de muy pocos miles de ejemplares y mantenidos como portavoces de las ideas de los respectivos políticos que los financiaban. En total, en Madrid, convivían cerca de treinta diarios, algunos con varias ediciones al día.

Todas estas publicaciones hicieron frente común, en mayor o menor medida, ante la grave problemática abierta. Desde sus editoriales se ensalzaron los históricos valores del honor y la patria, ansiando el momento en el cual los norteamericanos, conocidos y dibujados como cerdos, fueran aplastados para ejemplo del mundo entero. La palabra "patria" circulaba en boca de todos, pero lo que predominaba era el más cómodo de los patrioterismos. Todo el país gritaba a los cuatro vientos "guerra", pero al frente sólo marchaban aquéllos de clase más humilde, justo lo que no podían pagar las 2.000 pesetas de cuota que eximían del ejército. Cuando el conflicto se hizo inminente, en marzo $y$, sobre todo, abril, se multiplicaron las muestras de entusiasmo en favor de la lucha, mientras que, desde los periódicos, se comparaba el potencial de ambos ejércitos con resultados ridiculizadores hacia el bando considerado ya enemigo. De este modo se publicaba repetidamente que el armamento "yankee" era poco operativo y los soldados indisciplinados y apenas preparados para combatir contra las experimentadas tropas españolas. En varios diarios se llegó a escribir que, dada la carencia de fusiles, algunas formaciones 
norteamericanas realizaban la instrucción con escobas. A casi nadie se le pasaba por la imaginación la derrota frente a aquellos "advenedizos tocineros".

La prensa española, cada vez más contraproducente para con los intereses de la nación, se deshacía aún más en insultos y provocaciones, tachando a los norteamericanos de canallas, bandidos, mentirosos, escoria de la humanidad, etc. La publicación más combativa en este terreno fue El País, diario republicano revolucionario de vida muy agitada. El caso de este periódico es enormemente singular. Sus redactores, fieros partidarios de la guerra, atacaron siempre sin medida tanto a los norteamericanos como a todos los gobernantes españoles, empleando, pese a su ideología, las mismas armas sensacionalistas que el Journal y el World en los Estados Unidos. Sin embargo, poniendo en contradicción principios y acciones, se comportaron como los mayores críticos de las técnicas amarillistas, encuadrándolas dentro del más egoísta y sucio de los capitalismos. Desde mediados de abril publicaron cada día enormes titulares de varias líneas construidos a base de frases sentenciosas y con una finalidad impactante, acompañadas indistintamente de dibujos, gráficos, mapas y grandes caricaturas. "¡El País que viene bueno"; "El País que viene grave!", así se vendía en las calles el diario. A veces los titulares procedían de simples rumores de escaso fundamento, como el publicado el 7 de abril ("Asalto a la embajada de España en Washington", suceso nunca ocurrido) y la serie continua de alarmantes portadas alertando, en junio, acerca de la "inminente" invasión norteamericana a las Canarias y otros puntos de la península. También las revistas ilustradas fijaron más su atención en los nuevos asuntos de Cuba, ahora más vendibles que las corridas de toros y los asesinatos populares. La Ilustración Española y Americana, la publicación más venerable de todo el País, demostrará una escandalosa ceguera al realizar afirmaciones tan desmedidas como, por ejemplo, que la guerra era necesaria "por pedirla el instinto público y la ira, que ya no puede contenerse y estalla por lo ojos y las lenguas". Más dañinas resultaron las dos revistas ilustradas de contenidos más populares, Blanco y Negro y Nuevo Mundo. En ambas se encadenarán los chistes, caricaturas, menús, poesías y canciones sobre 
cerdos, así como toda clase de bromas fáciles rebosantes de un ridículo y mezquino sentido de la superioridad. Paralelamente aparecían por doquier crónicas sobre el heroico pasado, evocando la Reconquista, la colonización de América o las batallas de Lepanto, Bailén, etc. El como de los desatinos llegará con el nacimiento de El Marrano, semanario satírico ideado de modo íntegro para insultar y mofarse del enemigo norteamericano, de ahí su elocuente título.

Cuando llegó el primer batacazo, Cavite, se cuestionaron desde las mismas redacciones los telegramas recibidos, considerándolos falsos o manipulados por mano enemiga. Los editoriales habían pasado a un segundo lugar en detrimento de la última y más caliente información. Una orden militar acabó con el empleo de carteles y pizarras para dar cuenta, desde el exterior de las redacciones, de los nuevos movimientos en los campos de batalla. El telégrafo se había convertido en la más útil de las herramientas para el pueblo español. Lo recibido a primeros de mayo procedente de Manila parecía imposible de creer: ¡La armada española humillada por la norteamericana!. Al confirmarse las trágicas noticias el impacto fue brutal, todos los titulares de prensa reflejaron aquel "dolor nacional". Los periódicos se volcaron en el conflicto ejerciendo no de informadores, sino de jueces, estrategas militares 0 políticos. Las únicas publicaciones que no participaron en esta histeria colectiva fueron las federalistas, lideradas por $\mathrm{Pi}$ y Margall, que apostaban por la independencia cubana; y algunas revistas socialistas, como La Lucha de Clases y El Socialista, más preocupados por aspectos puramente ideológicos y por el ataque al sistema de cuotas que operaba para el reclutamiento militar. Las voces anarquistas tuvieron que buscar huecos en publicaciones ajenas, dada la represión que sufrían con motivo de recientes y sonados atentados. La prensa catalana fue, en su conjunto, más prudente y defensora de la paz, destacando en este sentido la labor de El Diluvio y El Diario de Barcelona, con continuos reproches hacia los procedimientos utilizados por los diarios madrileños. 
A partir del desastre de Santiago los periodistas más vocingleros fueron acallando sus voces, al tiempo que, como todo el mundo, miraban alrededor persiguiendo culpables fuera, y nunca dentro de sí mismas. Sin embargo, la sociedad española no acusaba los golpes sobre sus propias carnes. Dando la espalda a la realidad recurrirá al folclore o a la diversión, olvidando de un plumazo el honor defendido los días anteriores. La exaltación patriótica quedaba atrás, tan sólo cabía apreciar una cierta tristeza. Tras la derrota final todo el país entró en crisis. La prensa, el gobierno y el ejército fueron señalados como los principales culpables de lo que hoy, que no entonces, conocemos como desastre. Los periódicos se habían ganado a pulso el descrédito y la desconfianza del pueblo. Las principales plumas del país publicaron artículos evaluando el descalabro sufrido. Es cierto que hasta entonces brillantes escritores como Azorín, Baroja, Valle-Inclán, Clarín, Benavente, Blasco Ibáñez, Unamuno, Maeztu, Ganivet, etc., habían expresado sus opiniones en los más diversos diarios y revistas, pero a partir de ahora estas intervenciones serán mucho más numerosas y críticas. El movimiento intelectual que más indagará entre lo sucedido persiguiendo razones y soluciones será el "regeneracionismo", con Joaquín Costa a la cabeza. Todos estos autores coincidieron en afirmar que la prensa española era "culpable" frente al pueblo por haber incumplido con sus deberes, comenzando por el deber de información; mientras que los periodistas eran considerados en su conjunto como profesionales vagos, ineptos, de débil espíritu y en muchos casos favorecidos por alguna recomendación. Numerosas revistas de marcado carácter intelectual afloraron desde el pesimismo reinante. Con el tiempo se hablará de "Generación del 98", agrupación de autores hoy puesta en duda como tal. El pueblo, sintiéndose engañado y decepcionado, dejó de creer tan abiertamente en la opinión de los diarios y revistas de información general. Las tiradas descendieron y muchos periódicos iniciaron una lenta agonía hasta llegar, en pocos años, a la definitiva desaparición.

\section{Conclusión.}


Leopoldo Romeo, Director de La Correspondencia de España, resumirá en 1906, de un modo muy acertado, el estado en el cual quedaron las relaciones prensa-opinión pública tras el 98: La opinión es totalmente hostil a la Prensa y en ella tiene aún más desconfianza que en el resto de las clases sociales. Lee los diarios por conocer lo que en el mundo pasa, pero no los lee con convicción como antes, a ciegas. Pasó esa época en que los lectores pensaban como su diario, y ha sido reemplazada por otra en la cual los lectores, o desdeñan la opinión del periódico, o por lo menos de ella desconfíen, creyendo que es interesada, egoísta o tendenciosa.

\section{Bibliografía.}

AGUILERA, M. de (1998). "La investigación sobre comunicación en España: una visión panorámica". Comunicación y cultura. 1998

SAPERAS, E. (1998) Manual básico de teoría de la comunicación. CIMS, Barcelona, 1998. 